\title{
Application of the random key based electromagnetism-like heuristic for solving travelling salesman problems
}

\author{
Gezgin satıcı problemlerinin çözümü için rassal anahtar temelli \\ elektromanyetizma sezgiselinin uygulanması
}

\author{
Vildan ÖZKIR ${ }^{1}$ (iD), Burak TOPÇU⿱一𫝀) \\ 1,2Industrial Engineering Department, Machine Faculty, Yıldız Technical University, Istanbul, Turkey. \\ vildanozkir@gmail.com, burakt@yildiz.edu.tr
}

\begin{abstract}
Among network optimization problems, travelling salesman problem is widely studied one in the literature. Since the problem is computationally hard, many heuristics have been developed to obtain the optimal solution in reasonable time. This paper introduces a hybrid electromagnetism-like heuristics to solve symmetric travelling salesman problems. Originally, electromagnetism-like heuristic is a population based global search algorithm that is inspired by electromagnetism theory in Physics. The proposed mechanism is based on the principle of encouraging randomly generated particles to move toward to optimal solution in the feasible area. In this paper, randomkey approach is adapted to electromagnetism-like heuristic to solve vehicle routing problems. Regarding 15 benchmark instances, proposed heuristic procedure produces optimal solutions for small instances. Moreover, as the number of vertices increase in the network, the proposed algorithm generates near optimal solutions. Efficiency of results shows that the proposed algorithm can be evaluated for the solution of combinatorial optimization problems.
\end{abstract}

Keywords: Electromagnetism-like heuristic, Traveling salesman problems, Uncapacitated vehicle routing

\section{Introduction}

The traveling salesman problem (TSP) is an extensively studied classical combinatorial optimization problem that aims to find the optimal tour of $\mathrm{n}$ cities by minimizing the total traveling distance, beginning and terminating at the same location and visiting the other locations only one time. Although small instances can be solved for optimality by mixed integer programming, as the size of instances increase the TSP is remarkably challenging. Therefore, academicians published over a thousand articles, developing algorithms and methodologies to solve this problem more effectively [29].

Combinatorial optimization problems involve finding the best possible solution from a finite set of solutions fulfilling certain constraints. Since many combinatorial optimization problems are NP-hard, complete methods- that guaranties optimalityoften leads to high computation times for real-world applications [7]. Therefore, approximate methods are utilized to yield acceptable solutions in a significantly reduced computation time by sacrificing the guarantee of finding optimal solution.

The use of meta-heuristics is a rapidly growing field of research, especially for combinatorial optimization problems. Due to the theoretical and practical complexity of the problem,
Öz

Ăg optimizasyonu problemleri içerisinde, gezgin satıci problemi literatürde yaygın bir șekilde çalıșllan problemlerden biridir. Problemin hesaplama açısından zor olması dolayısıyla, optimal çözümü elverişli zamanda elde edebilmek için pek çok sezgisel algoritma geliștirilmiștir. Bu çalışma, simetrik gezgin satıcı problemlerinin çözümü için melez bir elektro-manyetizma sezgiseli sunmaktadir. Esasinda elektro-manyetizma sezgiseli, fizikteki elektromanyetizma teorisinden ilham alan, popülasyon tabanl global bir arama algoritmasıdır. Önerilen mekanizma, fizibil alanda rassal olarak olușturulan partikülleri optimal çözüme yaklaştırma prensibine dayanır. Bu çalıșmada, araç rotalama problemlerini çözebilmek için rassal anahtar yaklaşımı elektromanyetizma sezgiseline adapte edilmiștir. 15 klyaslama örneği üzerinde test edilen sezgisel yöntem küçük boyuttaki problemler için en iyi çözümleri üretmektedir. Ayrıca, ağdaki nokta sayısı arttıkça, önerilen algoritma optimale yakın çözümler üretmektedir. Sonuçların etkinliği, önerilen algoritmanın kombinatoryal optimizasyon problemleri çözümü için de değerlendirilebileceğini göstermektedir.

Anahtar kelimeler: Elektromanyetizma sezgiseli. Gezgin satıcı problemi, Kapasite kısıtsız araç rotalama researchers propose hybrid approaches by integrated meta-heuristics, ie. genetic-tabu search based algorithm [20]; ant colony-tabu search algorithm [18]. The inspiration behind hybridization of different algorithms is to utilize the best performing characteristics of various optimization techniques, that is, integrating these methods are accepted as a good idea [7].

In this study, we represent an adaption of electromagnetismlike (EML) algorithm approach to solve symmetric TSPs. Birbil and Fang [5] introduced EML heuristic for solving global optimization problems. EML heuristic utilizes an attracting-repelling mechanism to converge a solution for optimality. By constructing additional transformation procedures or hybridization with other search and meta-heuristic algorithms, many researchers successfully employed the algorithm for solving discrete and constrained optimization problems. Recently, EML algorithm has been used for computing eigenvalues and eigenvectors [34], redundancy allocation problem [36], prediction of diabetes mellitus [37], vehicle routing [38],[40], cell formation and layout problem [16], maximum betweenness problem [13], nurse scheduling [21], project scheduling [12], single machine scheduling [8]-[10],[30] and set covering problem [23]. 
The outline of this paper is as follows. In Section 2, a recent literature review on TSPs is presented briefly. In Section 3, the integrated methodology is introduced, underlying methods and their principles are explained in detail. Random key technique and the hybridization with EML algorithm are extensively discussed. In Section 4, computational results are presented. In Section 5, we present the results and our conclusions. Additionally, future research areas are discussed.

\section{Traveling salesman problem}

Among combinatorial optimization problems, the most prominent problem is generally referred as TSP. It generally intends to discover the optimal route among a given set of locations with beginning and ending at the same predefined location by focusing on the minimum travelling distance.

In this study, we consider a generic un-capacitated vehicle routing problem:

$$
\begin{gathered}
\text { Minimize } \sum_{i} \sum_{j} d_{i j} X_{i j} \\
\sum_{j} X_{i j}=1 \quad \forall i \\
\sum_{i} X_{i j}=1 \quad \forall j \\
\sum_{i \in S} \sum_{j \in S i \neq j} X_{i j} \leq|S|-1 \quad \forall S \\
X_{i j} \in\{0,1\} \quad \forall i \text { and } \forall j
\end{gathered}
$$

Where $X_{i j}$ is assigned to 1 if truck goes to node $j$ from node $i, 0$ otherwise. $d_{i j}$ is the distance between node $i$ and node $j$. Equation (1) is the objective function that minimizes the total routing distance. Equation (2) and Equation (3) ensure only one route between two nodes. Equation (4) is the sub-tour elimination constraint where $S$ is the subset of the cities and the representation of binary decision variables is given in Equation (5).

Researchers develop many approximate methods to resolve TSPs, as: self-organizing maps [3], simulated annealing [15], ant colony [1],[17],[28], tabu search [14],[27], a hybrid simulated annealing-tabu search algorithm [19], genetic algorithm [24], bat algorithm [25] particle swarm optimization [31], blind mole-rat algorithm [39], dynamic multiscale region search algorithm [41]. For further literature review on heuristic algorithms for TSPs, we refer Rego et al. [29]. Authors present an extensive survey for the primary heuristics and the specialized considerations accountable for their effective implementations. Additionally, they presented a computational analysis on the performance of these approaches on diverse set of symmetric and asymmetric TSP benchmark instances.

In recent years, hybridization of different approximate methods is getting more popular in order to effectively solve TSPs. By smart integration of heuristics, authors attempt to promote the advantages and eliminate the shortcomings of algorithms.

\section{Proposed algorithm}

The electromagnetism-like (EML) heuristic is presented to solve continuous unconstrained optimization problems. In this study, we integrate random key procedure to EML heuristic in order to solve constrained combinatorial optimization problems. The original EML heuristic can solve effectively test functions such as Rastrigin, Davis, Lavy and Kearfott functions in an appropriate computation time. Thus, we adapt the algorithm by embedding the random key procedure into it to solve sequencing and allocation problems.

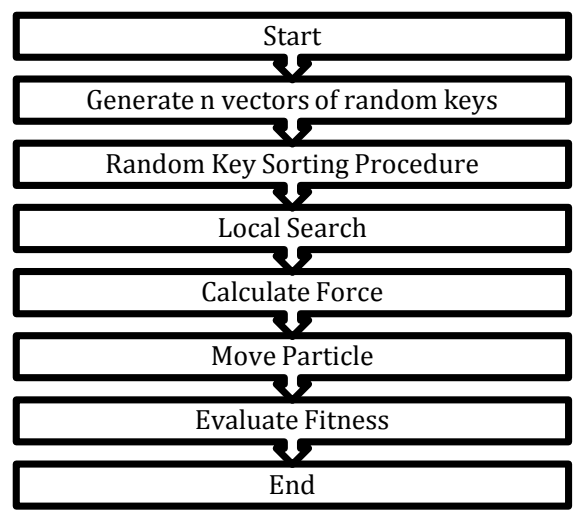

Figure 1: Proposed algorithm.

Figure 1 illustrates the hybrid random key EML heuristic. To represent these kinds of problems with random keys, $m$ position vectors have been generated.

Here, it should be noted that in original EML heuristic, the value of variable $k$ have been the $k^{\text {th }}(k \in n)$ random coordinate value of the particle $i(i \in m)$.

In this modified algorithm, the random numbers, which have been assigned into the cells of the position vector, are the coordinate values and the random key method is applied to the coordinates of particles [37].

\subsection{Electromagnetism-Like heuristic}

The EML heuristic is inspired from electromagnetism theory and Coulomb law. The algorithm proposes that there is an attracting/repelling effect between particles in the solution space. In elementary physics, it is known that electrically charged particles affect each other with respect to their relative charge magnitude and sign. Hence, two positively or two negatively charged particles repel each other, whereas particles, which have opposite signed charges, attract each other.

In EML algorithm, every particle's charge sign is assumed to be positive and the magnitude of the charge is expressed by its present objective function value. The algorithm implies that if a particle performs better by means of the objective function, it has a greater charge value, and vice versa. The charge of a particle expresses the level of attracting and/or repelling forces in the population. Therefore, highly charged particles attract remaining less charged particles of the population in order to converge to the optimal solution.

A classic population-based search approach proceeds on a set of feasible solutions. Similarly, EML heuristic proposed by Birbil and Fang [5], utilizes an attraction-repulsion mechanism to move these feasible points (solutions) toward optimality. Since EML heuristic works on a set of sample points, the number of particles (points) in the population should be determined. A main assumption is that the particles are uniformly distributed between a corresponding upper bound and a lower bound. The performance of each particle is 
evaluated in terms of predetermined objective function $f(x)$. Here, $f(x)$ is a minimization type objective function, $m$ is the size of population and $n$ is the dimension of the problem. The charge of a particle $i, q^{i}$, can mathematically be calculated as in Equation (6):

$$
q^{i}=\exp \left(-n \frac{f\left(x^{i}\right)-f\left(x^{\text {best }}\right)}{\sum_{k=1}^{m}\left(f\left(x^{k}\right)-f\left(x^{b e s t}\right)\right)}\right)
$$

Where $f\left(x^{\text {best }}\right)$ is the best level of objective for the current population.

The attracting mechanism encourages the points to move closer to better solutions, and conversely, the repelling mechanism encourages the points by moving away from worse ones [6]. All the particles in the population move along the resultant force that is exerted on them. After calculating the charges of the particles, in order to find to the movement direction of each particle the resultant force vector of each particle is calculated.

The resultant force vector $\mathrm{F}^{\mathrm{i}}$ of particle $\mathrm{i}$ is computed as in Equation (7).

$$
F^{i}=\sum_{j \neq i}^{m} \begin{cases}\left(x^{i}-x^{j}\right) \frac{q^{i} q^{j}}{\|\left(x^{i}-x^{j} \|^{2}\right.} \quad ; \quad f\left(x^{j}\right)<f\left(x^{i}\right) \\ \left(x^{j}-x^{i}\right) \frac{q^{i} q^{j}}{\|\left(x^{i}-x^{j} \|^{2}\right.} \quad ; \text { otherwise }\end{cases}
$$

In equation (7), the magnitude of the force which is exerted on particle $i$ emanated from particle $j$ is oppositely proportional to Euclidian distance between these particles. Additionally, the magnitude of force is proportionate to the charges of particles. Hence, higher force occurs between higher charged particles and contrarily lower force occurs between low charged particles. Unlike electrical charges, EML algorithm assigns no signs to the charge of an individual particle.

In order to define the direction of a particular force, algorithm compares the objective function values of particles. The total force vector exerted on each particle $F^{i}$ is computed by addition of each forces exerted on particle $i$. Since the direction of total exerted force depends on the location of particles, the particles, that turn out to be sufficiently close, may lead to a direction rather than the statistically projected gradient of $f$.

In EML algorithm, particles can move on the feasible region to find the optimal solution. This feasible region consists of the area between upper bound $\left(u_{k}\right)$ and lower bound $\left(l_{k}\right)$ of the $\mathrm{k}$ variables. RNG vector represents the feasible movements toward the upper bound, or the lower bound, for the corresponding dimension. As the resultant force vector $F^{i}$ is calculated, each particle moves toward its new position by a random step length $\lambda$. Here, $\lambda$ is generated regarding to standard uniform distribution with parameters $[0,1]$.

$$
x^{i}=x^{i}+\lambda \frac{F^{i}}{\left\|F^{i}\right\|}(R N G) i=1,2, \ldots, m .
$$

There exist four procedures in EML algorithm. The initialization phase is the first phase, which is employed for sampling feasible solutions. After calculating the objective values, local neighborhood search procedure start. The local procedure is employed for searching for a better refinement. The third procedure, CalcF, is utilized for calculating the total force exerted on each point, and the last procedure, Move, move a population of points toward optimality by maintaining feasibility. The pseudo-code of EML is given as follows:

Initialize()
$\mathrm{i}:=1$
while $\mathrm{i}<$ MAXITER do
Local(LSITER, $\delta$ )
$\mathrm{F}:=$ CalcF0
Move(F)
$\mathrm{i}:=\mathrm{i}+1$
endwhile
return result

\section{return result}

Here, $\delta \in[0,1]$ is the local search parameter, MAXITER corresponds to the maximum iteration number and LSITER corresponds to the maximum local search number and $m$ is the number of sample points (particles) in the search space.

\subsection{Random key technique}

Random key (RK) approach is firstly introduced by Bean [4] in order to attempt to overcome the difficulty of maintaining feasibility by using real-coded genetic algorithm to address a wide variety of combinatorial optimization problems.

Subsequently, numerous researchers employed this robust concept with different heuristics to find the optimal solution of combinatorial problems, as: Particle swarm algorithm [35] and genetic algorithms [32].

In order to calculate the minimum value of an objective function $f(x)$, an n dimensional position vector should be evaluated. An illustrative example is given as in Table 1 and Table 2:

Table 1: Generation i before RK technique.

\begin{tabular}{c|c|c|c|c|c|c|c|c|c}
\hline 1 & 2 & 3 & 4 & 5 & 6 & 7 & 8 & 9 & 10 \\
\hline 0.71 & 0.23 & 0.83 & 0.34 & 0.52 & 0.04 & 0.10 & 0.98 & 0.64 & 0.17 \\
\hline
\end{tabular}

Table 2: Generation i after RK technique.

\begin{tabular}{c|c|c|c|c|c|c|c|c|c}
\hline 6 & 7 & 10 & 2 & 4 & 5 & 9 & 1 & 3 & 8 \\
\hline 0.04 & 0.10 & 0.17 & 0.23 & 0.34 & 0.52 & 0.64 & 0.71 & 0.83 & 0.98 \\
\hline
\end{tabular}

For this example, the elements of the vector are sorted in the ascending order and the random key generator has generated $0.71,0.23$ and 0.83 for the first three elements. Since 0.71 is the $8^{\text {th }}$ largest number of the series, it will be assigned to the $8^{\text {th }}$ element of the vector. Before the transformation, the index of 1 associated to 0.71 will be assigned to the $8^{\text {th }}$ cell of the new vector, simultaneously. The second and third generated random numbers are 0.23 and 0.83 . They are respectively the $4^{\text {th }}$ and $9^{\text {th }}$ larger numbers of series. The index of 0.23 is 2 and the index of 0.83 is 3 . So, they will be assigned in the $4^{\text {th }}$ and $9^{\text {th }}$ cells of the new cells simultaneously. Thus, the new sequence $\{6,7,10,2,4,5,9,1,3,8\}$ will be generated.

The steps of random key technique can be summarized as: (i) for each cell of the vector, a random number is generated, (ii) $n$ random numbers are sorted in the ascending order and (iii) the corresponding indices of the random numbers are also sorted with respect to their random number position.

While utilizing the random key technique, a well-performing sorting algorithm is appropriate in terms of time complexity and computational processing speed. After sorting the all the 
values, the objective value of the new generation can be calculated.

\section{Application}

In this section, we investigate the efficiency of proposed algorithm in solving un-capacitated travelling salesman problem.

\subsection{Data}

The efficiency of the proposed method is discussed on the results of 15-known TSP instances, which can be found in (http://comopt.ifi.uni-heidelberg.de/software/TSPLIB95) TSPLIB in the literature. The problem instances and pertinent data is given in Table 3 . These test problems are chosen because there was data available in the literature to compare our results with those obtained by other heuristics in the literature.

\subsection{Results}

We summarized the results in Table 4 to illustrate the individual performance of proposed method.

By performing 35 trials for each problem instance, EML heuristics yield efficient results in small and medium size problems. As the number of vertices increases, the time needed for solution increases and convergence to optimality decreases. Figure 2 shows the average time needed for finding solution of the problem.

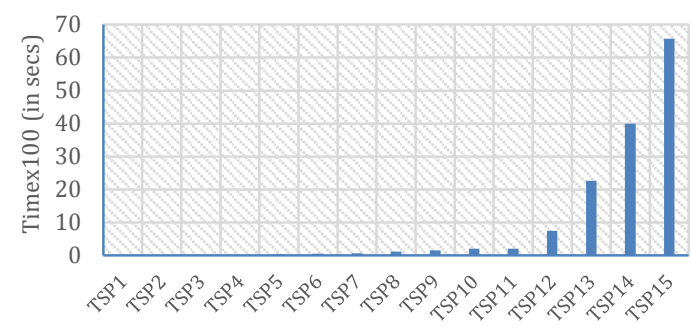

Figure 2: Required time in average for each problem.

\subsection{Comparative results}

For further investigation of the performance of proposed algorithm in solving TSPs, we compared the results of each problem obtained from 4 heuristic algorithms in the literature. These 15 problem instances in TSP library have been solved by the algorithms of Somhom et al. [33], Aras et al. [2], Cochrane and Beasley [11], Masutti and Castro [22] and proposed EML heuristics. Obtained results are given in Table 5.

Table 3: Data sets.

\begin{tabular}{|c|c|c|c|}
\hline Dataset ID & Data Set Name & \# of vertices & Best known solution \\
\hline TSP1 & eil51 & 51 & 426 \\
\hline TSP2 & berlin52 & 52 & 7542 \\
\hline TSP3 & ncit64 & 64 & 6400 \\
\hline TSP4 & eil76 & 76 & 538 \\
\hline TSP5 & kroA100 & 100 & 21282 \\
\hline TSP6 & eil101 & 101 & 629 \\
\hline TSP7 & $\operatorname{lin} 105$ & 105 & 14379 \\
\hline TSP8 & bier127 & 127 & 118282 \\
\hline TSP9 & $\operatorname{ch} 130$ & 130 & 6110 \\
\hline TSP10 & $\operatorname{ch} 150$ & 150 & 6528 \\
\hline TSP11 & kroA150 & 150 & 26524 \\
\hline TSP12 & kroA200 & 200 & 29368 \\
\hline TSP13 & $\operatorname{lin} 318$ & 318 & 42029 \\
\hline TSP14 & rat575 & 575 & 6773 \\
\hline TSP15 & rat783 & 783 & 8806 \\
\hline \multicolumn{4}{|c|}{ Table 4: Analysis of EML algorithm. } \\
\hline Dataset ID & Best with EML Heuristics & Worst with EML Heuristics & Deviation from Best Known (\%) \\
\hline TSP1 & 428 & 431 & $0.469 \%$ \\
\hline TSP2 & 7542 & 7748 & $0.000 \%$ \\
\hline TSP3 & 6400 & 6464 & $0.000 \%$ \\
\hline TSP4 & 545 & 560 & $1.301 \%$ \\
\hline TSP5 & 21810 & 22648 & $2.481 \%$ \\
\hline TSP6 & 648 & 662 & $3.021 \%$ \\
\hline TSP7 & 14901 & 15317 & $3.630 \%$ \\
\hline TSP8 & 121953 & 125362 & $3.104 \%$ \\
\hline TSP9 & 6435 & 6546 & $5.319 \%$ \\
\hline TSP10 & 6630 & 7089 & $1.563 \%$ \\
\hline TSP11 & 26866 & 30440 & $1.289 \%$ \\
\hline TSP12 & 31216 & 32687 & $6.293 \%$ \\
\hline TSP13 & 42896 & 45556 & $2.063 \%$ \\
\hline TSP14 & 7096 & 7665 & $4.769 \%$ \\
\hline TSP15 & 9354 & 10675 & $6.223 \%$ \\
\hline
\end{tabular}


Furthermore, we investigated the effects of parameter setting on computation times. Algorithm utilizes three parameters: these are number of particles $m$, maximum number of iterations for local search LSITER and maximum number of iterations for local search MAXITER. Figures 3a-3c illustrate the effects of these parameters on computation times. Parameter setting in this study is done by several random trials. We have done our computations with $2.20 \mathrm{GHz}$ and $2.0 \mathrm{~GB}$ RAM computer. The procedure is coded in Microsoft $₫$ Visual Basic $₫$ for Applications.

\section{Conclusions and discussions}

For improving valuable standards for the advancement of hybrid meta-heuristics. it will be important to enhance current approaches on algorithm development [7].
In this paper. we developed a hybrid procedure to solve uncapacitated TSPs. The proposed method has two phases. In the first phase, we proposed a procedure to initialize random solutions by excluding the problem constraints. Next, we utilized EML heuristics to improve the quality of obtained solution. We tested it on a set of TSP instances. The accuracy of results shows the algorithm performs well in terms of optimality. However, an extra effort is required to improve the computational time. We believe that modifying the code syntax or replacing the programming language with another programming language will yield efficient results in a reasonable computation time, especially for the problems that has higher dimensions.

Table 5: Comparative analysis of EML algorithm.

\begin{tabular}{|c|c|c|c|c|c|c|c|c|c|c|c|c|c|c|c|c|}
\hline \multirow{2}{*}{ ID } & \multirow[t]{2}{*}{$\begin{array}{c}\text { Best } \\
\text { Known }\end{array}$} & \multicolumn{3}{|c|}{ Somhom et al. [32] } & \multicolumn{3}{|c|}{ Aras et al. [2] } & \multicolumn{3}{|c|}{ Cochrane and Beasley [11] } & \multicolumn{3}{|c|}{ Masutti and Castro [22] } & \multicolumn{3}{|c|}{ Proposed Method } \\
\hline & & Mean & SD & Best & Mean & SD & Best & Mean & SD & Best & Mean & SD & Best & Mean & SD & Best \\
\hline TSP1 & 426 & 442.9 & 4.59 & 432 & 440.57 & 3.44 & 433 & 438.7 & 3.52 & 429 & 437.47 & 4.2 & 427 & 432.735 & 3.92 & 428 \\
\hline TSP2 & 7542 & 8363.7 & 241.82 & 7778 & 8025.07 & 248.79 & 7715 & 8073.97 & 270.14 & 7716 & 7932.5 & 277.25 & 7542 & 7737.25 & 259.66 & 7542 \\
\hline TSP3 & 6400 & 6594.07 & 72.97 & 6482 & 6547.6 & 66.02 & 6482 & 6400 & 0 & 6400 & 6400 & 0 & 6400 & 6423 & 33.69 & 6400 \\
\hline TSP4 & 538 & 563.2 & 6.45 & 554 & 562.27 & 5.23 & 552 & 556.1 & 8.03 & 542 & 556.33 & 5.3 & 541 & 550.70806 & 6.38 & 545.086 \\
\hline TSP5 & 21282 & 24678.8 & 862.09 & 23009 & 21616.77 & 164.21 & 21410 & 21868.47 & 245.76 & 21369 & 21522.73 & 93.34 & 21333 & 21666.264 & 161.66 & 21809.8 \\
\hline TSP6 & 629 & 665.93 & 7.27 & 655 & 655.57 & 5.95 & 640 & 654.83 & 6.57 & 641 & 648.63 & 3.85 & 638 & 648.50838 & 5.91 & 648.387 \\
\hline TSP7 & 14379 & 16111.37 & 609.1 & 14999 & 14475.6 & 118.24 & 14379 & 14702.23 & 328.37 & 14379 & 14400.17 & 44.03 & 14379 & 14650.344 & 274.935 & 14900.5 \\
\hline TSP8 & 118282 & 128920.3 & 6563.13 & 120110 & 121733.3 & 1240.04 & 119840 & 121780.3 & 1564.02 & 118760 & 120886.3 & 1158.79 & 118970 & 121419.55 & 1231.495 & 121953 \\
\hline TSP9 & 6110 & 6416.8 & 92.97 & 6265 & 6307.23 & 62.95 & 6203 & 6291.77 & 64.98 & 6142 & 6282.4 & 60.15 & 6145 & 6358.6829 & 65.2625 & 6434.97 \\
\hline TSP10 & 6528 & 6842.8 & 105.97 & 6634 & 6751 & 62.18 & 6631 & 6753.2 & 83.01 & 6629 & 6738.37 & 76.14 & 6602 & 6684.185 & 77.825 & 6630 \\
\hline TSP11 & 26524 & 29960.9 & 564.39 & 28948 & 27401.33 & 252.03 & 26930 & 27346.43 & 223.31 & 26932 & 27355.97 & 327.91 & 26678 & 27907 & 321.91 & 26866 \\
\hline TSP12 & 29368 & 33228.33 & 638.63 & 31669 & 30415.67 & 132.86 & 30144 & 30257.53 & 342.98 & 29594 & 30190.27 & 273.38 & 29600 & 31442.493 & 276.9625 & 31216 \\
\hline TSP13 & 42029 & 45832.83 & 541.67 & 44869 & 43922.9 & 382.29 & 43154 & 43704.97 & \begin{tabular}{|l|}
391.48 \\
\end{tabular} & 42975 & 43696.87 & 410.06 & 42834 & 43882.5 & 411.375 & 42896 \\
\hline TSP14 & 6773 & 8301.83 & 106.88 & 8107 & 7173.63 & 39.47 & 7090 & 7125.07 & 40.91 & 7039 & 7115.67 & 37.47 & 7047 & 7601.5 & 37.1825 & 7096 \\
\hline TSP15 & 8806 & 10721.6 & 108.81 & 10532 & 9387.57 & 39.44 & 9316 & 9326.3 & 48.45 & 9185 & 9343.77 & 46.97 & 9246 & 9943 & 48.9175 & 9354 \\
\hline
\end{tabular}

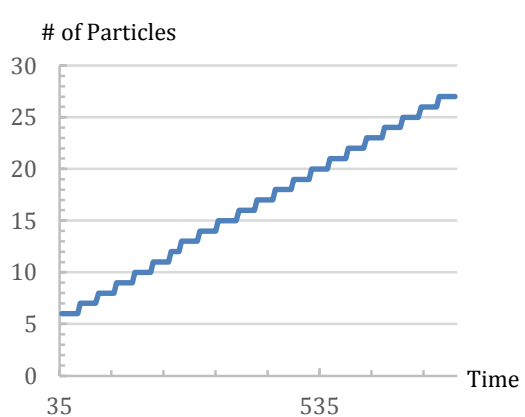

(a): Effect of number of particles $m$.

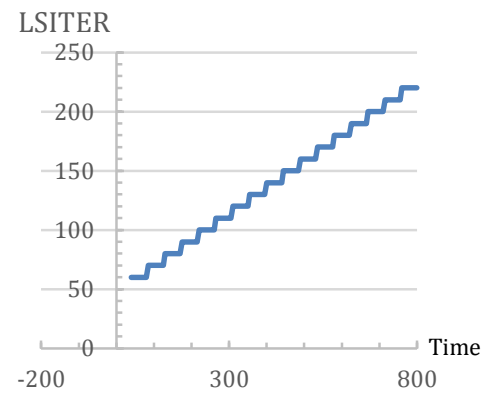

(b): Effect of LSITER.
MAXITER

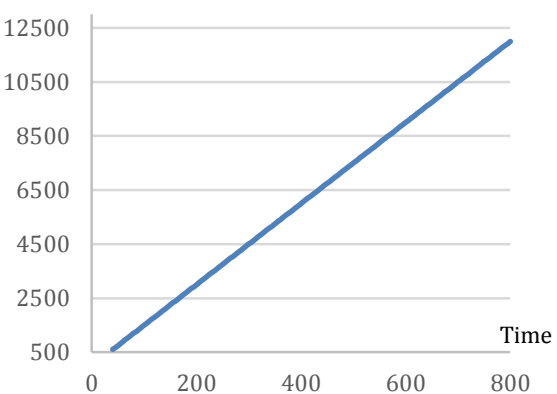

(b): Effect of MAXITER.

Figure 3: The effect of parameters on computation time. 
Additionally, the parameter setting in the two-phase EML algorithm has significant effect on the results and computation time, directly. If the parameter of $m$ (which denotes the number of particles) increases sufficiently, local search procedure ensures to converge or to find the optimal objective solution. However, simultaneously, this situation increases computation time too much and it decreases the practicality of the algorithm. Hence, parameter setting is crucial for the algorithm's performance.

Instead of local search procedure in the proposed method, simulated annealing algorithm can be utilized to increase the convergence to optimal objective solution. This hybrid approach will be explored in order to decrease the total computation time.

For future research, the proposed algorithm can be utilized to solve other combinatorial optimization problems. Additionally, multiple objective extensions of the algorithm and extensions handling uncertainty in the problem statement are other interesting topics in order to develop new heuristic algorithms especially for vehicle routing problems.

\section{References}

[1] Abd Aziz Z. "Ant colony hyper-heuristics for travelling salesman problem". Procedia Computer Science, 76, 534-538, 2015

[2] Aras N, Altinel KI, Oommen J. "A kohonen-like decomposition method for the traveling salesman problem: KNIESDECOMPOSE". 14th European Conference on Artificial Intelligence (ECAI), Berlin, Germany, 20-25 August 2000.

[3] Angeniol B, Vaubois GDLC, Texier JYL. "Self-organizing feature maps and the traveling salesman problem". Neural Networks, 1(4), 289-293, 1988

[4] Bean JC. "Genetic algorithms and random keys for sequencing and optimization". ORSA Journal on Computing, 6(2), 154-160, 1994.

[5] Birbil Sİ, Fang SC. "An electromagnetism-like mechanism for global optimization". Journal of Global Optimization, 25(3), 263-282, 2003.

[6] Birbil Sİ, Fang SC, Sheu RL. "On the convergence of a population-based global optimization algorithm". Journal of Global Optimization, 30(2-3), 301-318, 2004.

[7] Blum C, Puchinger J, Raidl GR, Roli A. "Hybrid metaheuristics in combinatorial optimization: A survey". Applied Soft Computing, 11(6), 4135-4151, 2011.

[8] Chang PC, Chen SH, Fan CY. "A hybrid electromagnetismlike algorithm for single machine scheduling problem". Expert Systems with Applications, 36, 1259-1267, 2009.

[9] Chao CW, Liao CJ. "A discrete electromagnetism-like mechanism for single machine total weighted tardiness problem with sequence-dependent setup times". Applied Soft Computing, 12, 3079-3087, 2012.

[10] Chen SH, Chang PC, Chan CL, Mani V. "A hybrid electromagnetism like algorithm for the single machinescheduling problem". Lecture notes in Computer Sciences, 4682, 543-552, 2007.

[11] Cochrane EM, Aras N. "The co-adaptive neural network approach to the euclidean travelling salesman problem". Neural Networks 16(10), 1499-525, 2004.
[12] Debels D, Vanhoucke M. "The electromagnetism metaheuristic applied to the resource-constrained projectscheduling problem". Lecture Notes in Computer Science, 3871, 259-270, 2006.

[13] Filipovic V, Kartelj A, Matic D. "An electromagnetism metaheuristic for solving the maximum betweenness Problem". Applied Soft Computing, 13, 1303-1313, 2013.

[14] Gendreau M, Laporte G, Semet F. "A tabu search heuristic for the undirected selective travelling salesman problem", European Journal of Operational Research, 106, 539-545, 1998.

[15] Geng X, Chen Z, Yang W, Zhao, K. "Solving the traveling salesman problem based on an adaptive simulated annealing algorithm with greedy search". Applied Soft Computing, 11, 3680-3689, 2011.

[16] Jolai F, Tavakkoli-Moghaddam R, Golmohammadi A, Javadi B. "An Electromagnetism-like algorithm for cell formation and layout problem". Expert Systems with Applications, 39, 2172-2182, 2012.

[17] Jun-Man K, Yi Z. "Application of an Improved Ant Colony Optimization on Generalized Traveling Salesman Problem". Expert Systems with Applications, 17, 319-325, 2012.

[18] Lin Y, Yeh CH, Huang PS. "A hybrid ant-tabu algorithm for solving a multistate flow network reliability maximization problem". Applied Soft Computing, 13(8), 3529-3543, 2013.

[19] Lin Y, Bian Z, Liu X. "Developing a dynamic neighborhood structure for an adaptive hybrid simulated annealing-tabu search algorithm to solve the symmetrical traveling salesman problem". Applied Soft Computing, 49, 937-952, 2016.

[20] Mantawy AH, Abdel-Magid YL, Selim SZ. "A new geneticbased tabu search algorithm for unit commitment problem". Electric Power Systems Research, 49(2), 71-78, 1999.

[21] Maenhout B, Vanhoucke M. "An electromagnetic metaheuristic for the nurse-scheduling problem". Journal of Heuristics, 13, 359-385, 2007.

[22] Masutti TAS, Castro LND. "A self-organizing neural network using ideas from the immune system to solve the traveling salesman problem". Information Sciences, 179(10), 1454-1468, 2009

[23] Naji-Azimi Z, Toth P, Galli L. "An electromagnetism metaheuristic for the unicost set covering problem". European Journal of Operational Research, 205, 290-300, 2010.

[24] Nagata Y, Soler D. "A new genetic algorithm for the asymmetric traveling salesman problem". Expert Systems with Applications, 39, 8947-8953, 2012.

[25] Osaba E, Yang XS, Diaz F, Lopez-Garcia P, Carballedo R. "An improved discrete bat algorithm for symmetric and asymmetric traveling salesman problems". Engineering Applications of Artificial Intelligence, 48, 59-71, 2016.

[26] Pasti R, Castro LND. "A neuro-immune network for solving the traveling salesman problem". International Joint Conference on Neural Networks, Vancouver, Canada, 16-21 July 2006.

[27] Pedro O, Saldanha R. "A Tabu Search Approach for the Prize Collecting Traveling Salesman Problem". Electronic Notes in Discrete Mathematics, 41, 261-268, 2013. 
[28] Ramtake D, Kumar S, Patle VK. "Route Optimization by Ant Colony Optimization Technique". Procedia Computer Science, 92, 48-55, 2016.

[29] Rego C, Gamboa D, Glover F, Osterman, C. "Traveling salesman problem heuristics: Leading methods, implementations and latest advances". European Journal of Operational Research, 211, 3, 2011, 427-441, 2011.

[30] Sels V, Vanhoucke M. "A hybrid Electromagnetism-like Mechanism/tabu search procedure for the single machine-scheduling problem with a maximum lateness objective". Computers and Industrial Engineering, 67, 44-55, 2010.

[31] Shi XH, Liang YC, Lee HP, Lu C, Wang QX. "Particle swarm optimization-based algorithms for TSP and generalized TSP". Information Processing Letters, 103, 169-176, 2007.

[32] Snyder LV, Daskin MS. "A random-key genetic algorithm for the generalized traveling salesman problem". European Journal of Operational Research, 174(1) 38-53, 2006.

[33] Somhom S, Modares A, Enkawa T. "A self-organizing model for the traveling salesman problem". Journal of the Operational Research Society, 48(4-6), 919-928, 1997.

[34] Taheri SH, Ghazvini H, Saberi-Nadjafi J, Biazar J. "A hybrid of the restarted Arnoldi and electromagnetism metaheuristic methods for calculating eigenvalues and eigenvectors of a non-symmetric matrix". Applied Mathematics and Computation, 191, 79-88, 2007.

[35] Tasgetiren MF, Sevkli M, Liang YC, Gencyilmaz G. "Particle swarm optimization algorithm for makespan and total flowtime minimization in permutation flowshop sequencing problem". European Journal of Operational Research, 177(3), 1930-1947, 2007.
[36] Teimouri M, Zaretalab A, Niaki STA, Mani Sharifi M. “An efficient memory-based electromagnetism-like mechanism for the redundancy allocation problem". Applied Soft Computing, 38, 423-436,2016.

[37] Wang KJ, Adrian AM, Chen KH, Wang KM. "An improved electromagnetism-like mechanism algorithm and its application to the prediction of diabetes mellitus". Journal of Biomedical Informatics, 54, 220-229, 2015.

[38] Wu P, Yang KJ, Huang BY. "A revised EM-like mechanism for solving the vehicle routing problems". $2^{\text {nd }}$ International Conference on Innovative Computing, Information and Control 2007-ICICIC '07 Proceedings 181, Kumamoto, 5-7 September 2007.

[39] Yıldırım T, Kalaycı CB, Mutlu Ö. "A novel metaheuristic for traveling salesman problem: blind mole-rat algorithm". Pamukkale Üniversitesi Mühendislik Bilimleri Dergisi, 22(1), 2016, 67-70.

[40] Yurtkuran A, Emel E. "A new hybrid electromagnetismlike algorithm for capacitated vehicle routing problems". Expert Systems with Applications, 37, 3427-3433, 2010.

[41] Zhang H, Zhou J. "Dynamic multiscale region search algorithm using vitality selection for traveling salesman problem". Expert Systems with Applications, 60, 81-95, 2016. 